\title{
Инвазионные виды растений в Промышленновском районе Кемеровской области
}

\section{Invasive plant species in Promyshlennovsky District, Kemerovo Region}

\author{
Филиппова А. В., Пинигина Ю. А., Романова Н. Г., Степанюк Г. Я., Тарасова И. В. \\ Filippova A. V., Pinigina Y. A., Romanova N. G., Stepanyuk G. Y., Tarasova I. V. \\ Кемеровский государственный университет, г. Кемерово, Россия.E-mail: sasha1977@ngs.ru \\ Kemerovo State University, Kemerovo, Russia
}

\begin{abstract}
Peфераm. Анализируется видовой состав растений, включенных в Черную книгу флоры Сибири (2016), обитающих в Промышленновском районе Кемеровской области. Выявлено 18 видов инвазионных растений из 10 семейств, среди которых преобладают однолетние травы. Чужеродные виды Промышленновского района расселяются и натурализуются в нарушенных местообитаниях: на свалках, мусорных кучах, пустырях, по обочинам дорог, у жилья. Некоторые проникают в естественные сообщества. Большинство видов занесены из Северной Америки или Средиземноморья, и по времени заноса являются неофитами, по способу заноса - ксенофитами, по степени натурализации - колонофитами и эпекофитами.
\end{abstract}

Ключевые слова. Адвентивные растения, инвазионные виды, Кемеровская область, Черная книга, чужеродные виды.

Summary. The species composition of plants included in the Black Book of Siberian Flora (2016) inhabiting Promyshlennovsky District of the Kemerovo Region is analyzed. 18 species of invasive plants from 10 families were identified, among which annual grasses predominate. Alien species of the Promyshlennovsky District are settled and naturalized in disturbed habitats: in landfills, garbage heaps, vacant lots, along roadsides, near dwellings. Some of them penetrate to the natural communities. Most of the species are brought from North America or the Mediterranean, and by the time of drift are neophytes, by the method of drift - xenophytes, by the degree of naturalization - colonophytes and epecophytes.

Key words. Adventure plants, alien species, Black Book, invasive species, Kemerovo Region.

Инвазионные растения являются проблемой для аборигенной флоры региона. Их стремительная адаптация является в настоящее время значительной частью высокомасштабных природных изменений и зачастую приводит к существенным потерям биологического разнообразия и экономической значимости экосистем. В настоящее время для каждого региона Сибири составлены списки чужеродных видов. В Кемеровской области из 58 инвазионных видов, включенных в Черную книгу флоры Сибири (2016), зарегистрировано 48.

Целью настоящего исследования является изучение инвазионных видов в Промышленновском районе Кемеровской области, занесенных в Черную книгу флоры Сибири.

При изучении флоры большое внимание уделяется заносным (адвентивным) видам, появление которых - одна из сторон антропогенной эволюции растительности. Наиболее агрессивными являются адвентивные виды, выделенные в особую группу - инвазионные виды. Термин «инвазионный вид» широко применяется к заносным видам растений, которые вне естественного ареала оказались способны к активному размножению и расселению, нередко вытесняя виды местной биоты (Виноградова и др., 2010).

Промышленновский район расположен на западе Кемеровской области в центральной части Кузнецкой котловины. Его площадь составляет 3,1 тыс. кв.км (3,2 \% площади Кемеровской области). 
Из них 78,7 \% - сельскохозяйственные земли (в том числе 50,4 \% - пашня), 17,3 \% - леса. Через территорию района проходят железная и несколько автомобильных дорог, связывающие административные районы Кемеровской области между собой, а также с соседними регионами РФ. По плотности населения Промышленновский район является одним из самых густонаселенных (15,3 человека на 1 кв. км). Также здесь располагаются Ушаковское, Солоновское и другие месторождения каменного угля, которые являются достаточно перспективными для добычи. В значительной степени эти факторы обуславливают расселение адвентивных видов растений.

С востока на запад район пересекает река Иня - приток Оби, разделяющая его на две части северную лесостепную и южную степную. По югу проходит пограничная полоса Салаирского кряжа (Промышленновский район, 2019).

Материалом для исследований послужили гербарные сборы авторов, а также коллекция Гербария Кемеровского государственного университета (КЕМ). Основными точками сбора являлись следующие населенные пункты и их окрестности: д. Журавлево, д. Пушкино, д. Пьяново, д. Танай, д. Тарасово, п. Плотниково, п. Промышленная, с. Васьково, с. Калтышино, с. Окунево, с. Уфимцево, ст. Падунская, ст. Промышленная.

В результате исследований выявлено 18 видов инвазионных растений из 10 семейств (табл.), что составляет 37,5 \% от всех инвазионных видов Кемеровской области. Самым многочисленным является семейство Asteraceae (4 вида - 22,2 \% от инвазионных видов Промышленновского района), за ним следует семейство Brassicaceae Burnet. (3 вида - 16,6 \%). Три семейства, а именно: Apiaceae Lindl., Cuscutaceae Dumort., Poaceae (R. BR.) Barnhart - насчитывают по 2 вида. В остальных семействах - по 1 виду.

В 2015 г. был составлен список инвазионных растений России (Виноградова и др., 2015), который включает в себя более 200 видов. При этом 24 вида являются общими для всех регионов Российской Федерации. В Промышленновском районе из этого списка произрастает 8 видов (33,3 \%). К ним относятся: Echinocystis lobata (Michx.) Torr. et A. Gray, Hordeum jubatum L., Acer negundo L., Lepidotheca suaveolens (Pursh) Nutt., Armoracia rusticana Gaertn., Lactuca serriola L., Conyza canadensis (L.) Cronquist, Saponaria officinalis L. Общих видов для европейской части России и Сибири насчитывается 29, в Промышленновском районе из них зарегистрировано всего 2 вида - Echinochloa crusgalli (L.) Beauv. и Lepidium densiflorum Schrad. Сибирь и Дальний Восток имеют по 8 общих инвазионных видов, в Промышленновском районе из них отмечено 2 вида (Centaurea pseudomaculosa Dobrocz. и Pastinaca sativa L.).

Среди инвазионных растений Промышленновского района преобладают однолетние травы (11 видов - 61,2 \%). Двулетние и многолетние травы представлены в равных долях (по 16,6 \% каждой биоморфы). Древесные растения представлены всего одним видом (Acer negundo L.). Виды рода Cuscuta являются паразитами (табл.).

Инвазионные виды отличаются по уровню агрессивности и степени внедрения в различные сообщества. Согласно классификации А. А. Нотова с соавторами (2010) выделяют четыре инвазионных статуса.

Среди чужеродных видов, произрастающих в Промышленновском районе, 8 видов (44,5 \%) расселяется и натурализуется в нарушенных местообитаниях (статус 3). В ходе дальнейшей натурализации некоторые из них, по-видимому, смогут внедриться в полуестественные и естественные сообщества (табл.).

Почти в равных долях представлены чужеродные виды, активно расселяющиеся и натурализующиеся в нарушенных полуестественных и естественных местообитаниях (статус 2), и потенциально инвазионные виды, способные к возобновлению в местах заноса и проявившие себя в смежных регионах в качестве инвазионных видов (статус 4). На долю этих двух групп приходится почти половина инвазионных видов Промышленновского района (49,9\%).

Один вид - Acer negundo L. является видом-«трансформером» (статус 1). Такие виды активно внедряются в естественные и полуестественные сообщества, изменяют облик экосистем, нарушают сукцессионные связи, выступают в качестве эдификаторов и доминантов, образуя значительные по площади одновидовые заросли, вытесняют и (или) препятствуют возобновлению видов природной флоры. 
Таблица

Видовой состав инвазионных видов растений Промышленновского района Кемеровской области

\begin{tabular}{|c|c|c|c|c|c|c|}
\hline № & Вид & Семейство & Биоморфа & $\begin{array}{c}\text { Местооби- } \\
\text { тание }\end{array}$ & Естественный ареал & $\begin{array}{l}\text { Инвазион- } \\
\text { ный статус }\end{array}$ \\
\hline & Acer negundo L. & Aceraceae Juss. & Дерево & $\begin{array}{l}\text { Мусорная } \\
\text { свалка } \\
\end{array}$ & Северная Америка & 1 \\
\hline & $\begin{array}{l}\text { Armoracia rusti- } \\
\text { cana Gaertn. }\end{array}$ & $\begin{array}{c}\text { Brassicaceae } \\
\text { Burnet. }\end{array}$ & Мн/лет. & $\begin{array}{l}\text { Мусорная } \\
\text { свалка }\end{array}$ & Средиземноморье & 3 \\
\hline & $\begin{array}{l}\text { Axyris } \\
\text { amaranthoides L. }\end{array}$ & $\begin{array}{c}\text { Chenopodiaceae } \\
\text { Vent. }\end{array}$ & 1/лет. & $\begin{array}{l}\text { Обочина } \\
\text { дороги }\end{array}$ & Даурия & 4 \\
\hline & $\begin{array}{l}\text { Centaurea } \\
\text { pseudomaculosa } \\
\text { Dobrocz. }\end{array}$ & Asteraceae Juss. & 2/лет. & $\begin{array}{l}\text { Обочина } \\
\text { дороги }\end{array}$ & $\begin{array}{c}\text { Восточная Европа, } \\
\text { Западная Азия }\end{array}$ & 3 \\
\hline & $\begin{array}{l}\text { Conium } \\
\text { maculatum L. }\end{array}$ & Apiaceae Lindl. & 2/лет. & Пустырь & $\begin{array}{c}\text { Европа, Западная и } \\
\text { Средняя Азия, Кавказ }\end{array}$ & 2 \\
\hline & $\begin{array}{l}\text { Conyza } \\
\text { canadensis (L.) } \\
\text { Cronquist }\end{array}$ & Asteraceae Juss. & 1/лет. & $\begin{array}{l}\text { Мусорная } \\
\text { куча }\end{array}$ & Северная Америка & 3 \\
\hline & $\begin{array}{l}\text { Cuscuta europaea } \\
\text { L. }\end{array}$ & $\begin{array}{c}\text { Cuscutaceae } \\
\text { Dumort. }\end{array}$ & 1/лет. & Ивняки & $\begin{array}{l}\text { Северная Америка, } \\
\text { Средиземноморье }\end{array}$ & 4 \\
\hline & $\begin{array}{l}\text { Cuscuta } \\
\text { lupuliformis } \\
\text { Krock. }\end{array}$ & $\begin{array}{l}\text { Cuscutaceae } \\
\text { Dumort. }\end{array}$ & 1/лет. & $\begin{array}{c}\text { Заросли } \\
\text { кустарника }\end{array}$ & $\begin{array}{c}\text { Западная и Восточная } \\
\text { Европа }\end{array}$ & 4 \\
\hline & $\begin{array}{l}\text { Echinochloa } \\
\text { crusgalli (L.) } \\
\text { Beauv. } \\
\end{array}$ & $\begin{array}{c}\text { Poaceae (R. BR.) } \\
\text { Barnhart }\end{array}$ & 1/лет. & $\begin{array}{l}\text { Обочина } \\
\text { полевой } \\
\text { дороги } \\
\end{array}$ & Южная Азия & 3 \\
\hline & $\begin{array}{l}\text { Echinocystis loba- } \\
\text { ta (Michx.) Torr. } \\
\text { at A. Gray }\end{array}$ & $\begin{array}{l}\text { Cucurbitaceae } \\
\text { Juss. }\end{array}$ & 1/лет. & $\begin{array}{l}\text { Заросли } \\
\text { ивняка }\end{array}$ & Северная Америка & 2 \\
\hline & $\begin{array}{l}\text { Hordeum jubatum } \\
\text { L. }\end{array}$ & $\begin{array}{c}\text { Poaceae (R. BR.) } \\
\text { Barnhart }\end{array}$ & 1/лет. & $\begin{array}{l}\text { Обочина } \\
\text { дороги }\end{array}$ & $\begin{array}{l}\text { Северная Америка, } \\
\text { Восточная Сибирь }\end{array}$ & 2 \\
\hline & $\begin{array}{l}\text { Lactuca serriola } \\
\text { L. }\end{array}$ & Asteraceae Juss. & 1/лет. & $\begin{array}{c}\text { Обочина } \\
\text { дороги }\end{array}$ & Средиземноморье & 3 \\
\hline & $\begin{array}{l}\text { Lepidium } \\
\text { densiflorum } \\
\text { Schrad. }\end{array}$ & $\begin{array}{l}\text { Brassicaceae } \\
\text { Burnet. }\end{array}$ & 1/лет. & $\begin{array}{c}\text { Разнотрав- } \\
\text { но-злаковая } \\
\text { степь } \\
\end{array}$ & Северная Америка & 3 \\
\hline & $\begin{array}{l}\text { Lepidotheca } \\
\text { suaveolens (Pursh) } \\
\text { Nutt. }\end{array}$ & Asteraceae Juss. & 1/лет. & $\begin{array}{l}\text { Обочина } \\
\text { дороги, у } \\
\text { жилья }\end{array}$ & $\begin{array}{l}\text { Восточная Азия, } \\
\text { северная Америка }\end{array}$ & 4 \\
\hline & $\begin{array}{l}\text { Pastinaca sativa } \\
\text { L. (Pastinaca } \\
\text { sylvestris Mill.) }\end{array}$ & Apiaceae Lindl. & 2/лет. & $\begin{array}{l}\text { Обочина } \\
\text { дороги }\end{array}$ & Средиземноморье & 2 \\
\hline & $\begin{array}{l}\text { Saponaria offici- } \\
\text { nalis L. }\end{array}$ & $\begin{array}{l}\text { Caryophyllaceae } \\
\text { Juss. }\end{array}$ & Мн/лет. & $\begin{array}{l}\text { Обочина } \\
\text { дороги }\end{array}$ & $\begin{array}{c}\text { Европа, Юго-Запад- } \\
\text { ная Азия } \\
\end{array}$ & 3 \\
\hline & $\begin{array}{l}\text { Trifolium hy- } \\
\text { bridum L. }\end{array}$ & Fabaceae Lindl. & Мн/лет. & $\begin{array}{l}\text { Обочина } \\
\text { дороги }\end{array}$ & $\begin{array}{c}\text { Европа, Кавказ, Ма- } \\
\text { лая Азия }\end{array}$ & 2 \\
\hline & $\begin{array}{l}\text { Velarum officinale } \\
\text { (L.) Reichenb. (Si- } \\
\text { symbrium officina- } \\
\text { le (L.) Scop.) }\end{array}$ & $\begin{array}{l}\text { Brassicaceae } \\
\text { Burnet. }\end{array}$ & 1/лет. & $\begin{array}{l}\text { Обочина } \\
\text { дороги, у } \\
\text { жилья }\end{array}$ & $\begin{array}{c}\text { Европа, Кавказ, } \\
\text { Северная Африка, } \\
\text { Балкано-Малоазиат- } \\
\text { ская область }\end{array}$ & 3 \\
\hline
\end{tabular}

Примечание: биоморфа: мн/лет. - многолетнее травянистое, 1/лет. - однолетнее травянистое, 2/лет. - двулетнее травянистое. Инвазионный статус - пояснения статусов см. в тексте. 
Почти все изученные инвазионные виды произрастают в нарушенных местообитаниях: на свалках, мусорных кучах, пустырях, по обочинам дорог, у жилья. Некоторые из них проникают в естественные сообщества, такие как ивняки, кустарниковые заросли. К ним относятся Cuscuta europaea L., Cuscuta lupuliformis Krock., Echinocystis lobata (Michx.) Torr. et A. Gray. Один вид - Lepidium densiflorum Schrad. - обнаружен в разнотравно-злаковой степи. В целом местообитания изученных видов не отличаются от таковых на территории всей Кемеровской области (Ковригина и др., 2014), где доля сельхозугодий и нарушенных земель лесного фонда составляет почти треть (Доклад о состоянии..., 2017).

Большинство инвазионных видов были занесены из Северной Америки или Средиземноморья и имели североамериканский, средиземноморский или североамериканско-средиземноморский, североамериканско-восточносибирский ареалы. Некоторые виды проникли с Кавказа и Европы, либо из Северной Африки и Западной, Средней или Восточной Азии (табл.).

По времени заноса все изученные виды относятся к неофитам. Исключение составляет вид Pastinaca sativa L., который является археофитом (Эбель, 2012).

По способу заноса преобладают виды-ксенофиты, которые попали в регион непреднамеренно. К ним относится 11 видов $(61,2 \%)$. В два раза меньше численность эргазиофитов - видов, культивируемых и сбегающих из культуры. К этой группе принадлежит 6 видов (33,2 \%): Acer negundo L., Armoracia rusticana Gaertn., Echinocystis lobata (Michx.) Torr. et A. Gray, Pastinaca sativa L. (Pastinaca sylvestris Mill.), Saponaria officinalis L., Trifolium hybridum L. Один вид - Hordeum jubatum L. - является ксено-эргазиофитом.

По степени натурализации виды Промышленновского района распределились на две группы: колонофиты (11 видов - 61,2\%) и эпекофиты (7 видов - 38,8 \%).

Таким образом, предварительный анализ видов растений Промышленновского района, занесенных в Черную книгу флоры Сибири, показывает, что на сравнительно небольшой территории произрастает более трети видового разнообразия «чернокнижников» Кемеровской области. Дальнейшее изучение, вероятнее всего, выявит новые виды этих растений.

\section{ЛИТЕРАТУРА}

Виноградова Ю. К., Абрамова Л. М., Акатова Т. В., Аненхонов О. А., Анкипович Е. С., Антипова Е. М., Антонова Л. А., Афанасьев В. Е., Багрикова Н. А., Баранова О. Г., Борисова Е. А., Борисова М. А., Бочкин В. Д., Буланый Ю. И., Верхозина А. В., Владимиров Д. Р., Григорьевская А. Я., Ефремов А. Н., Зыкова Е. Ю., Кравченко А. В., Крылов А. В., Куприянов А. Н., Лавриненко Ю. В., Лактионов А. П., Лысенко Д. С., Майоров С. Р., Меньшакова М. Ю., Мещерякова Н. О., Мининзон И. Л., Михайлова С. И., Морозова О. В., Нотов А. А., Панасенко Н. Н., Пликина Н. В., Пузырев А. Н., Раков Н. С., Решетникова Н. М., Рябовол С. В., Сагалаев В. А., Силаева Т. Б., Силантьева М. М., Стародубцева Е. А., Степанов Н. В., Стрельникова Т. О., Терехина Т. А., Тремасова Н. А., Третьякова А. С., Хорун Л. В., Чернова О. Д., Шауло Д. Н., Эбель А. Л. «Черная сотня» инвазионных растений России // Совет ботанических садов стран СНГ при Международной ассоциации Академий наук: Информационный бюллетень. - М., 2015. - Вып. 4 (27). - С. 85-89.

Виноградова Ю. К., Майоров С. Р., Хорун Л. В. Черная книга Средней полосы России. - М.: Геос, 2010. $512 \mathrm{c}$.

Доклад о состоянии и охране окружающей среды Кемеровской области в 2016 году. - Кемерово, 2017. 448 c. [Электронный ресурс]. - 2019. Режим доступа: http://ecokem.ru/doklady-o-sostoyanii-okruzhayushhej-sredykemerovskoj-oblasti/, свободный.

Ковригина Л. Н., Тарасова И. В., Филиппова А. В. Основные местообитания инвазионных видов во флоре Кемеровской области // Растительность Восточной Европы и Северной Азии: мат. межд. науч. конф. (29 сентября -3 октября 2014). - Брянск: ГУП «Брянское полиграфическое объединение», 2014. - С. 70-71.

Нотов А. А., Виноградова Ю. К., Майров С. Р. О проблеме разработки и ведения региональных Черных книг // Российский журнал биологических инвазий, 2010. - № 4. - С. 54-86. [Электронный ресурс]. - Режим доступа: http://www.sevin.ru/invasjour/issues/2010_4/Notov_10_4.pdf, свободный.

Промышленновский район. Краткая характеристика [Электронный ресурс]. - 2019. Режим доступа: http:// admprom.ru/, свободный. 
Черная книга флоры Сибири / Науч. ред. Ю. К. Виноградова, отв. ред. А. Н. Куприянов. - Новосибирск: Академическое изд-во «Гео», 2016. - 440 с.

Эбель А. Л. Инвазионные виды во флоре северо-западной части Алтае-Саянской провинции // Проблемы промышленной ботаники индустриально развитых регионов: Матер. III Междунар. конф. (Кемерово, 18-19 сентября 2012 г.). - Кемерово, 2012. - С. 133-135. 